\title{
EMBEDDING CHANGEMAKER SKILLS AND SOCIAL INNOVATION INTO DESIGN STUDENT LEARNING
}

\author{
Friedemann SCHABER, Rebecca FAKOUSSA, Carys REDFERN, Henrietta FARRUGIA \\ and Michael WRIGHT \\ University of Northampton, United Kingdom
}

\begin{abstract}
Building on entrepreneurship education and the United Kingdom (UK) government review on creativity in business, this paper discusses a case study of a funded project to develop design students' future skills by collaborating on transitioning student projects into start-up venture and commercialisation for the common good. Undergraduate students are shown to gain insights from different faculties and each other's subject expertise using a variety of set activities throughout the academic year to challenge and support them. The learning for students included scheduled workshops with the possibility of new venture creation based on the new product development (NPD) methodology, student networking and applying their soft skills in a new context. Four workshop tasks (Enterprise, innovation and you, enterprise development, prototyping and venture articulation) were developed for this project and visualised in a route map. The collaboration of product design students with entrepreneurship students has been observed at the commencement stage, during and after the experience to understand their personal development and identify key learnings captured through opinion polls, focus groups and observation. Triangulation resulted through focus group and feedback from wider project team and academics reflecting on learning models in design/engineering versus entrepreneurship/business. This project is timely due to its year-long inter-faculty student experience during a pandemic using and developing 'changemaker' competencies and social innovation.
\end{abstract}

Keywords: Changemaker, co-creation, collaboration, social innovation, student researcher

\section{INTRODUCTION}

In the showcased project, design and entrepreneurship students took part in a series of scheduled activities throughout the academic year 2020-21 that have challenged and supported them. They gained insights from different faculties, through collaboration and the subject expertise across Design and Business Entrepreneurship studies. This showcase demonstrates the enhancement of the Changemaker Certificate, which is an employability initiative developed by the University of Northampton, itself a UK based partner institution of an international collaboration around social innovation, called Ashoka Universities [1].

The learning for students included four facilitated workshops with the possibility of new venture creation based on the new product development (NPD) methodology, student networking and applying their soft skills in a new context.

In the discussion, the suitability of workshops and visual guidelines for university use will be highlighted and the evaluation of student engagement and entrepreneurial activity shared. Students become potential siloed in their faculty or school of thought - this cross-faculty cooperation supports their development towards $\mathrm{T}$ shaped learners, with deep understanding and breadth of collaborative expertise [2].

This project changes practice at an UK university, developing an iterative model and toolkit for cross collaboration, aided by a visual road map of journey and start-up facilitation. This model builds on the Design Council's Double Diamond Design Process [2] and St Galler Start-up Navigator [3]. Upon completion of the workshop activities, the authors conclude that the inquiry forms a clear argument for the implementation of such initiatives for the benefit of all stakeholders involved.

\section{METHODS}

The paper aims to present and discuss the methods used to work collaboratively across disciplines and the methods used to embed social innovation skills into cross-faculty student learning. The project 
delivery has been built around the support from two undergraduate student researchers, which were recruited to act as 'Academic Brokers' and collected data throughout. Students as researchers is an innovative pedagogy aimed at influencing undergraduates to become submersed in their academics by inheriting research skills through co-creating within their future field of work. A partnership is formed between teacher and student to investigate issues often found within the academic workplace.

\subsection{Entrepreneurship methods overview}

Entrepreneurship teaching focusses on the entrepreneurial mindset, Business Model, Strategy and Business Formation. Predominant learning styles provided in entrepreneurship teaching are the taught delivery of subject knowledge in textbook format and live case study, delivered through discussions in workshop format, fostering critical thinking and presentation skills. The project added to the programmes problem-based learning approach and ensured the 'live' aspect despite the pandemic.

\subsection{Design methods overview}

In this project, the Design Thinking methods of visual concepts [2], co-creation [4], and rough prototyping with sketch, 3D doodles and wireframes have been provided to the participating students, through set activities in a prototyping workshop format and communicated, as follows: "This time the focus is on Prototyping. How well do you know your user experience UX from your user interface UI? We will (virtually) take you to the design workshops and Makerspace in the Creative Hub, demonstrating rapid prototyping technologies including laser cutting and 3D printing. Followed by an introduction to top app prototyping tools and a taste of Adobe XD”.

\subsection{Collaborative methods of working together}

The project has deployed new collaborative innovation toolkits with students, namely problem tree exercise, exploring the causes and effects of a problem, Gamestorming [5], Visual Thinking [6], and an introduction to prototyping of screen-based applications using 'wireframes' and user experience design tools for mobile apps, developed by Adobe Systems.

Whilst challenged by the global pandemic, the project workshops have all been delivered online. Virtual Learning Environment (VLE) by Blackboard and the Online Canvas for Visual Collaboration by Miro have been used to conduct the workshops and other student interactions. Both design students and entrepreneurship students were working towards new venture articulation, learning aspects of New Product Development and they had the opportunity to use the project as evidence to gain an optional extracurricular qualification, called 'Changemaker Certificate', with three levels of attainment which were classified as Bronze, Silver or Gold. The university defines Changemaker as "spotting a social or environmental problem and having the skills and determination do something about it" and are defined as to "live responsibly, work collaboratively, be resourceful, practice empathy, remain true to your personal values" [1]. The changemaker values were at the heart of the project, the projects aims and the project team.

\section{PROJECT, PROCESS AND WORKSHOPS}

The aim of the workshop series was to support students to develop their employability skills whilst embracing social innovation. This has been facilitated through engaging the students in social innovation in the context of learning, fostering student's abilities in terms of communication, networking, presentation, and team-building skills. In addition, the workshop series provided the possibility for startup ventures [3] and of gaining insightful experience by means of collaborating with staff and students with different sets of expertise and visualised in the roadmap diagram in Figure 1. Together, in five cross-faculty teams the students practiced social innovation, co-creation, and prototyping, by creating design proposals, storyboards, and wireframes - resulting in apps, products and services that are going to address the big social and economic issues [4].

The project team included 18 BA Business Entrepreneurship students, matched by 18 BSc Product Design students, two student researchers and two senior academics involved in the workshop facilitation. Activities and dissemination were supported by the project team that consisted of student researchers, Learning Technologist, Librarian, Employability Department staff and a Graphic Designer. 'Students as researchers' was an innovative pedagogy aimed at influencing undergraduates to become submersed in their academic environment by cultivating research skills through co-creating within their future field of work. A partnership was formed between teacher and student to investigate issues 
concerned. The project team had met in online planning meetings ahead of workshops and in a subsequent debrief where reflections were gathered. Student researchers were mentored for the delivery of workshops, presentation styles and project management. Evaluation was undertaken through focus group and feedback from the project team and academics, reflecting on learning models in design engineering versus entrepreneurship/business models.

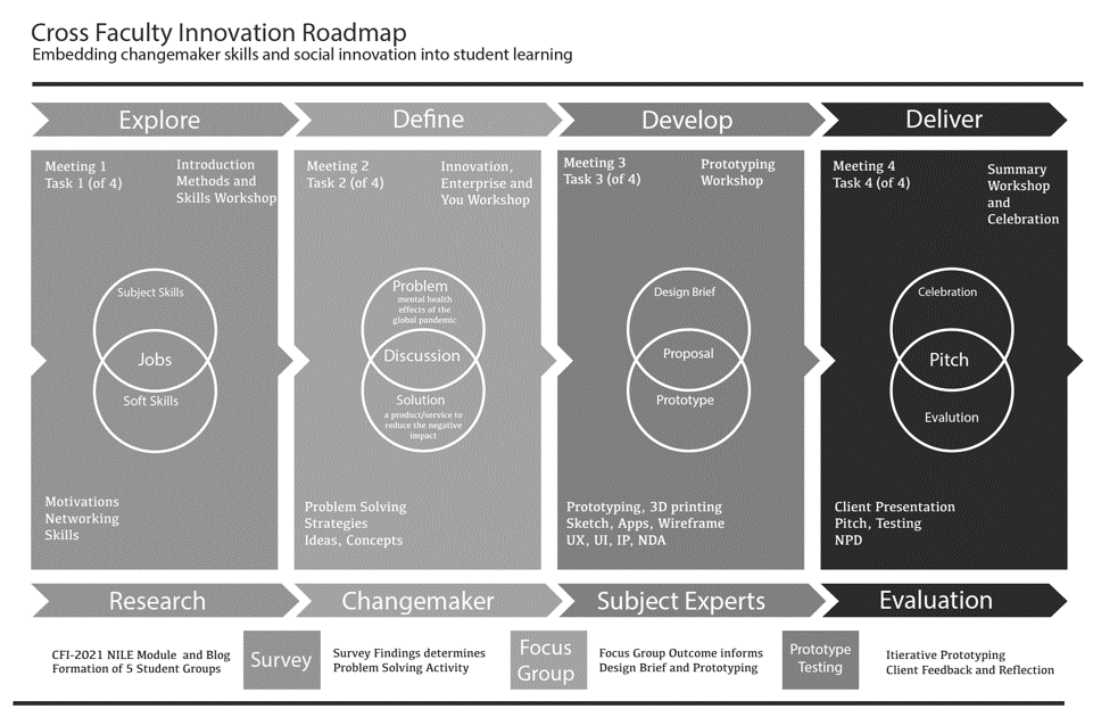

Figure 1. Student groups from two faculties attend four virtual workshops. Process visualised in a roadmap diagram

Embedded in the cross-collaboration activities, students learnt to jointly address a social issue: the decline of mental health of university students during lockdown. Projects resulted in a number of outputs, such as the joint creation of a design brief, 4 of which defined apps for mental health and 1 service. These have subsequently been prototyped to proof-of-concept stage, for testing and evaluation. The students were tasked to "Create a) a brief (Outline Design Proposal) in bullet point format and b) visualise the app/service through a Mindmaps / storyboard / wireframe model. The brief and the visual was handed over to UX Designers, for execution or refinement of app/service idea." As briefed by the student team, prototypes were then developed in a suitable software package (Adobe XD) to be ready for demonstration in workshop four and examples shown in Figure 2.
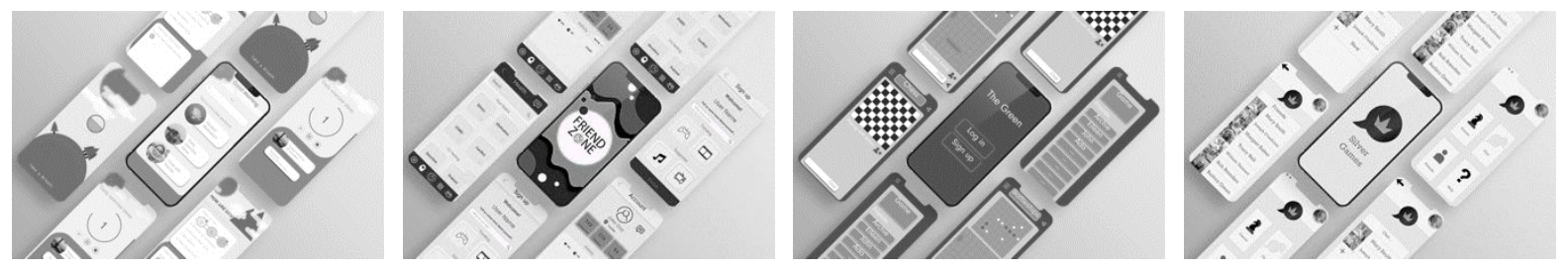

Figure 2. Prototyping workshop outcomes. Four Mental Health Apps, created in Adobe XD

\section{FINDINGS}

Quantitative and qualitative forms of student evaluation were collected via opinion polls (survey) across all 4 workshops, see Graph 1. In addition, students' remarks were collated during the virtual classrooms, discussion in breakout rooms as well as focus groups. Different aspects have been looked at including innovation, teamwork, collaboration, leadership, visual thinking, application of changemaker skills as well as students' experiences whilst working with clients and the mechanism of project management. It was evident how such feedback allowed the designers to fully understand artistic/display communication i.e., how they can make it easier for everyone to understand and interact with, as well as helping students express themselves in giving a brief. The findings demonstrate the excitement of mixing theoretical information and knowledge with creative skills and expression. 

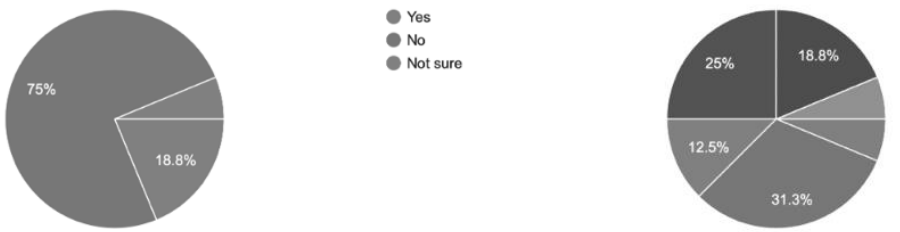

- Support for your assignments

- Potential future collaborations / work

- Developing your Network

- Learning real world skills

- Being exposed to something new and

- Being part of a trailblazing project

Educating others on what we do within

FAST, and how are skill sets are useful
to yourselves.

Graph 1. Visualisation of collaborative experiences and expectations from the initial survey

\subsection{Findings from survey and workshop sessions}

This paper focuses on the key areas including collaborations, soft skills (time management and networking) and self-improvement/self-development. The second workshop survey (a key question) asked - What are three things that you take away from today? From the responses, the networking was seen as very important, Examples of students' voice include:

\begin{tabular}{|l|l|}
\hline Student & Comment \\
\hline 1 & "Multidisciplinary team building skills, Time management \& Networking" \\
\hline 7 & "Good to teamwork and collaborate" \\
\hline 5 & "Friends, ideas, skills" \\
\hline
\end{tabular}

Students had wide ranging opinions, which appeared on both ends of the spectrum with some identifying similarities and differences between themselves. Students commented:

\begin{tabular}{|l|l|}
\hline Student & Comment \\
\hline 3 & "Perspectives are different, Collective thinking is interesting...." \\
\hline 4 & $\begin{array}{l}\text { "Working with people that think differently to me allows me to be more creative } \\
\text { interacting with others, different perspectives, design insight..." }\end{array}$ \\
\hline 6 & $\begin{array}{l}\text { "A wider knowledge of what both faculties have in common, as oppose of how different } \\
\text { they both are..." }\end{array}$ \\
\hline
\end{tabular}

Students also identified hesitations and 'worry' about being involved in something so new, which felt daunting and outside of the 'norm' and their discipline.

\begin{tabular}{|l|l|}
\hline Student & Comment \\
\hline 2 & $\begin{array}{l}\text { "Leaving with less nervousness, greater clarity on why we are doing this collaboration } \\
\text { and the opportunity it brings through a different pathway of thinking and executing } \\
\text { tasks..." }\end{array}$ \\
\hline
\end{tabular}

The responses highlighted the importance of networking, new connections, knowledge of processes in another faculty, ranking the key skills seen important to employment, as drawn up in Graph 2. Contrary to expectations the soft skills of communication and time management have been substantially higher valued than the subject expertise in Product Design or Entrepreneurship being important to employment.

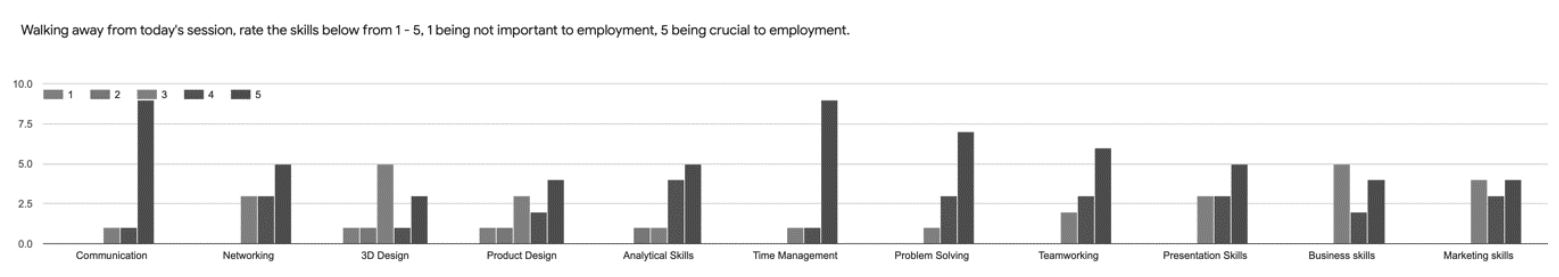

Graph 2. Ranking of employability skills from the second workshop survey

During session 3, the student researchers joined-in the VLE's breakout rooms, probing disciplinary expertise. Students discussed different ways of pitching - selling yourself, not just the product. They considered how to promote themselves and their app service, using personality and storytelling. This highlighted to the students the alternative perspectives outside of their discipline. For the 'design students' it had been about the design aspect. The focus on being able to demonstrate the skills, while 
for the entrepreneurship students the focus had been on the market opportunity. Further, business students wanted more research to ensure they knew all aspects (the more research/info the better), while design students highlighted that did not want to do too much research for fear of jeopardizing their creation and influencing their own creativity. This showcased an important disciplinary difference and enhanced the discussions. Further, BSc Product Design students commented on improved business acumen while BA Business Entrepreneurship students increased their understanding of NPD, briefing and physical development of product. By the fourth workshop, tensions and groupwork issues started, developed and have been resolved with self-development and growth identified by students. They explained how their collaboration skills improved:

\begin{tabular}{|l|l|}
\hline $\begin{array}{l}\text { S2 "They improved definitely! Since it was hard } \\
\text { to communicate with others over [the VLE], it } \\
\text { has improved since then." }\end{array}$ & $\begin{array}{l}\text { S4 "Better communication with new } \\
\text { acquaintances, taking on natural leadership } \\
\text { role". }\end{array}$ \\
\hline $\begin{array}{l}\text { S5 "Facing challenges in Multidisciplinary } \\
\text { team. Being able to support others in their } \\
\text { projects." }\end{array}$ & $\begin{array}{l}\text { S6 "providing me the chance to network with the } \\
\text { students [from the other faculty]." }\end{array}$ \\
\hline
\end{tabular}

While other students highlighted the initial challenges of communication and how they improved how they worked together towards a mutual goal, many suggested their favourite part of the workshops was the identifying and working together initially on the creative side and experiencing different ways of working.

\begin{tabular}{|l|l|}
\hline $\begin{array}{l}\text { S1 “... where we got to breakout into our groups } \\
\text { to discuss our project." }\end{array}$ & $\begin{array}{l}\text { S9 “... where we came together to brainstorm an } \\
\text { idea to work on going forward”" }\end{array}$ \\
\hline & $\begin{array}{l}S 7 \text { ".. provided the chance to engage with } \\
\text { students from the other faculty." }\end{array}$ \\
\hline
\end{tabular}

\subsection{Findings from Focus Groups}

The focus group led by a student researcher, for pedagogical and research reasons, used 11 questions to ask each of the groups about their overall experience of working together. Two key areas of results were identified: employability skills linked to communication and collaboration.

Students identified how much the experience had helped them grow and develop skills which they would later use. Quotes included:

\begin{tabular}{|l|l|}
\hline $\begin{array}{l}\text { FG1: "Communication is key for finding a job. } \\
\text { This has made me more comfortable working } \\
\text { with others." }\end{array}$ & $\begin{array}{l}\text { FG5: "I don't think I would have talk to someone } \\
\text { outside my faculty to learn about their course or } \\
\text { faculty }\end{array}$ \\
\hline $\begin{array}{l}\text { FG5: "Solving a problem or solving an issue I I } \\
\text { am trying to move out from my angle and see } \\
\text { it from another person's perspective." }\end{array}$ & $\begin{array}{l}\text { FG2: "Presentation of things forced me to think a } \\
\text { bould I place things to make them more attractive" }\end{array}$ \\
\hline
\end{tabular}

Further, students reflected on how important working together had been and how giving them time and a reason to talk had strengthened tentative relationship and showed how future working practices had been positively influenced. Quotes included:

\begin{tabular}{|l|l|l|}
\hline $\begin{array}{l}\text { FG2: "I had met her before as we are both } \\
\text { students' reps and had met before, but this gave } \\
\text { us a chance to talk more" }\end{array}$ & $\begin{array}{l}\text { Follaborating outside of product design" } \\
\text { colmade me less scared about }\end{array}$ \\
\hline
\end{tabular}

Initial reflection of the feedback received was positive, with support of cross-faculty development within the university. Upon completion of the focus groups, students who attended were offered the opportunity to develop an online profile linked to the external facing blog. This is used to showcase the ongoing work with the intention of uncovering potential employment opportunities.

\section{DISCUSSION}

As drawn out from the survey and questionnaires, students become potential siloed in their faculty or school of thought - this cross-faculty cooperation support students' development towards $\mathrm{T}$ shaped learners which is characterised by deep understanding and also a breadth of collaborative expertise [2]. Students might have developed 'habits' of working in their siloes - for example, in future, 
entrepreneurship students might need to work with product designers. This collaboration was good practice and very much replicates real- life that they could encounter [4]. Further, Design students have taught using non-siloed language entrepreneurship students how to use a 3D printer thereby acquiring new future-proof skill sets [7]. Soft skills and employability skills - Varied business acumen and design knowledge exist across learners - peer to peer learning enhances students understanding as well as the ability to work and learn together [8]. Presenting, networking, and building rapport has been practiced in online sessions to which exposed students to different environments.

This cross-faculty experience led to different learning for each part of the team which led to rich data and future research opportunities which are explored in further papers. The findings showed that social innovation is a topic of interest for students and relevant to students lives. This paper identifies that more resources are needed to support students to develop the space and skills to embed further knowledge and practice in the safety of a university setting. Cross-faculty, while not a new concept, relies in addition to the Changemaker values, on trust and communication between faculties, which themselves are siloed. To date, only limited guidelines are available on working together across faculties in a university setting; this research aims to fill this gap and progress criteria for sustained collaboration by developing an iterative model as visualised in Figure 1, exploring Changemaker methodology [1].

Finally, this paper demonstrates learning typologies, kinaesthetic approaches (i.e., prototyping and learning by doing, exemplified in Figure 2) and synergies with other pedagogic research across faculties by creating a model to help other learners and academics to embed social innovation and Changemaker.

\section{CONCLUSIONS}

In conclusion, the relevance of joint Entrepreneurship and Product Design students' learning from an institutionally funded project has been highlighted. The findings demonstrate the experiences, results, and skills improvements from across the projects. Throughout the project a series of structured activities has been used to support employability skills, including networking across the faculties, problem solving and new product development (NPD), devising a design brief and undertaking App development in an industry standard prototyping tool (Adobe XD).

The activities resulted in a dedicated VLE Organisation Module, the co-creation of app prototypes that address the decline of mental health in students during lockdown and student's recognition of their own personal growth and development of working with other disciplines. The paper explores the enterprise and innovation facilitation, informs 'Changemaker' competencies and proposes an iterative model of collaboration for other faculties and universities to consider.

\section{REFERENCES}

[1] University of Northampton. Changemaker at the University of Northampton [online]. Available: https://www.northampton.ac.uk/student-life/changemaker/ [Accessed 2020, 16 November].

[2] Brown T. Eleven lessons: Managing design in eleven global brands. A study of the design process [online]. Available:

https://www.designcouncil.org.uk/sites/default/files/asset/document/ElevenLessons_Design_Cou ncil\%20(2).pdf [Accessed 2021, 16 March].

[3] Grichnik D. and Hess M. 2020. Start-up navigator - Guiding your entrepreneurial journey. London: Red Globe Press.

[4] Sanders E. B. N. and Stappers P. J. 2008. Co-creation and the new landscapes of design. Co design. 4(1), pp.5-18.

[5] Gray D., Brown S., and Macanufo J. 2010. Gamestorming: A playbook for innovators, rulebreakers, and changemakers. Sebastopol: O'Reilly Media.

[6] Brand W. and Koene P. 2017. Visual thinking: Empowering people and organisations through visual collaboration. Amsterdam: BIS Publishers.

[7] Creative \& cultural skills. Building a creative nation: The next decade [online]. Available: https://ccskills.org.uk/downloads/CCS_BUILDINGACREATIVENATION_WEB_SINGLES.pdf [Accessed 2021, 1 March]

[8] Davies A., Fidler D., and Gorbis M. 2011. Future work skills 2020 [online]. Available: https://www.iftf.org/uploads/media/SR-1382A_UPRI_future_work_skills_sm.pdf [Accessed 2021, 20 May]. 